\title{
30 LEARNING AND TEACHING QUALITATIVE RESEARCH: A VIEW FROM THE REFERENCE DISCIPLINES OF ANTHROPOLOGY AND HISTORY
}

\author{
Bonnie Kaplan \\ Yale University School of Medicine \\ U.S.A.
}

Jonathan Liebenau London School of Economics and Political Science United Kingdom

Michael D. Myers University of Auckland New Zealand

Eleanor Wynn University of Oregon U.S.A.

\section{Introduction}

As interest grows in qualitative methods, more attention is being focused on how to teach others to carry out qualitative research projects. Qualitative research has roots in social science and humanities disciplines. Over the years, individuals in these disciplines have honed data collection and analysis techniques and developed approaches to understanding through a variety of descriptive and interpretive methods. Their methods include obser- 
vation, participation, close reading of texts, and, more recently, data analysis techniques such as discourse analysis, hermeneutic interpretation, and grounded theory. In many cases, these researchers articulated and practiced ways of understanding the points of view of the individuals they study (be this focused on a text, an historical development, or a ritual practice). They then went deeper by using additional theoretical knowledge together with additional evidence to interpret and explain the situation under study. They also may have incorporated methods and epistemological stances from other fields, developing such areas as cliometrics in history, ethnoscience in anthropology, and the widespread use of sophisticated statistical analysis in sociology and psychology.

Just as we in IS have learned from methodological work in these other fields, we also can learn about teaching these methods by examining the educational approaches they employ. By adapting not only the methods, but also how they are taught to graduate students, we may both deepen our understanding of these forms of inquiry and how to teach them to others.

This panel is comprised of IS researchers who hold doctorates in reference disciplines for qualitative research. With credentials and publications in both IS and other fields, the panelists may speak to issues of teaching and evaluating qualitative research in IS in ways that bring perspectives from reference disciplines and that are well grounded in personal experiences in both the reference discipline and in IS. The focus in this panel is on teaching, and particularly on educating graduate students in qualitative research. Panelists will discuss how this material has been taught in their base disciplines and raise issues for how it should be taught in IS in the future. They will describe how they and other students learned the methods, the research questions, and the standards for good work in their doctoral fields. They will discuss how they themselves adapted their training for doing IS research, how they teach research methods in IS, and what they recommend for teaching qualitative research in IS in the future. Following the panelists' remarks, the chair will invite the audience to discuss with panelists what we may learn by looking at ways of adapting reference discipline research and teaching methods when teaching IS research.

The panel is comprised of historians and anthropologists. Between them, these two disciplines use a wide range of qualitative and interpretive research approaches. Historians have, for centuries, been experts in analyzing texts and historical artifacts to develop explanatory narratives of events as they unfold over time. Anthropologists have developed well established expertise in studying and explaining culture by immersing themselves in it. History and anthropology represent disciplines that do research involving immersion in other settings and vast amounts of textual, verbal, and observational data to make sense of dynamic situations. In both fields, too, newer quantitative approaches have been combined with more traditional qualitative research approaches. Having two panelists from each of these disciplines provides a more thorough overview of each of the reference disciplines: how they evolved over time, how they are taught in different universities, how each panelist has used this knowledge to contribute to IS, and changes each of them have seen in these approaches as used in IS. Together, these two disciplines provide a view of how research in IS, and particularly qualitative research, may be taught, practiced, and evaluated. 


\section{Panelist Statements}

Bonnie Kaplan: I took a faculty position in information systems immediately upon completing a doctorate in history at a school that values interdisciplinarity, and where history is considered as a field in both the social science and humanities. My work draws on the kinds of questions social scientists and humanists ask, and on methods used by them for answering such questions. My graduate program emphasized traditional historical narrative based on original documents as primary source material. Methodological and theoretical issues were implicit and interpretive approaches were such an established tradition that they were more assumed than discussed in graduate courses and departmental seminars. Graduate students read numerous (several each week) historical books and papers together with original documents in several fields within the discipline, covering different time periods, places, issues, and interpretations. They then spend many years (at my school, it was not unusual for a Social Sciences Division student to take over 10 years) doing the research for a dissertation. I worked on the history of computer use in clinical medicine by analyzing original source material of medical computing publications, historical and sociological literature pertaining to medicine and to technology, and by engaging in participant observation as a programmer/analyst at two academic hospitals. I since have conducted studies of information systems in clinical settings by using a combination of methods: ethnographic interviewing, participant observation, observation, surveys, and document analysis.

Today, methodological approaches are addressed more explictly both in graduate history courses and in historical writing than when I was a graduate student. I will discuss how I learned to do history and how students learn it today. I will talk about how, later, as a researcher and teacher in both information systems and medical informatics, I learned how to make methods explicit and how to combine them with quantitative methods to achieve robust, rigorous, and relevant research results. Based on these experiences, I believe that what makes for good research, whether qualitative or quantitative, must be partially self taught and internalized. While helpful, research methods courses, checklists, and guidelines are secondary to steeping oneself in models of excellent research through apprenticeship and emulation and then personally undertaking a significant project to develop both mastery and originality.

Jonathan Liebenau: As a student of history in the 1970s, I was much influenced by the renewed debate on the use of quantitative methods (dubbed "cliometrics" at the time, but in principle not different from much of the economic history of the 1930s and some of the social history of the 1960s). All historians who were interested in methodology had to engage in that debate, and many of us developed work that brought out the relationship between the qualitative methods, which had been very well crafted by historical scholarship, and "new" quantitative methods. I find it easy to defend either approach, and I believe very strongly that both are legitimate (and that those who attempt to de-legitimate qualitative methods are very seriously misguided). Furthermore, I find it easy to demonstrate the great value of carefully executed qualitative methods used in many social sciences, especially history, anthropology, and sociology.

Michael D. Myers: I will discuss how I learned to do textual analysis and observation. After majoring in anthropology and psychology at the undergraduate level, I went on to specialize in Social Anthropology for my Master's and Ph.D. I will discuss 
how a doctoral student in anthropology was expected to have read and understood the ethnographic works of anthropologists from many different schools (e.g., Malinowski, Geertz, Radcliffe-Brown, Boaz, Benedict, Godelier, Levi-Strauss, Firth, Turner, etc). The differences between these schools were regularly discussed and debated (e.g., the functionalism of Radcliffe-Brown versus the structuralism of Levi-Strauss). Ph.D. students, however, would typically become disciples of one particular approach and use that approach in their fieldwork. In my case, I used critical hermeneutics to analyze and interpret my ethnographic materials. I spent 14 months doing fieldwork studying the independence movement in Vanuatu (a group of islands in the South-West Pacific).

I will argue that one of the key challenges for qualitative researchers in information systems is that of superficiality. How can we expect doctoral students in IS to produce good qualitative research if they have completed just one or two courses in qualitative methods? I will argue that this superficiality is one of the main reasons why so many qualitative research articles are rejected in our top journals (although this is not to say that the rejection rate for quantitative articles is any lower). I will suggest a few ways in which this challenge might be overcome.

Eleanor Wynn: When I went to Xerox PARC as an intern in 1976, I was both fascinated with the altogether new-to-me world of computing as well as struck with how totally my world-view differed from the one around me. It took many years of acculturation before I was able to tell people they were asking the wrong question when they asked me "What is your instrument?" There actually is an answer: my instrument is my brain and the repeated exposure to a form of viewing and analyzing that comes with an apprenticeship in anthropology and conversation analysis. But in the beginning I had felt compelled to come up with some "technic." I was struck by how most people consider themselves social analysts (they are, but not at an academic level) and with the fact that once you point out something previously unarticulated, it is, of course, obvious. It therefore quickly becomes "not special." Everyone possesses a sort of lumpen social science. This is the premise of ethnomethodology, the theoretical view I specialized in, based in phenomenology.

What is different about specializing in social analysis is the review of theories and results of others' studies and formation of patterns and arguments based in this. Part of my work as a person bridging the worlds of social science, technology, and business, was to grasp how powerful these tools are for practical application, something that wasn't a goal in graduate school. By taking the everyday and relatively unactionable insights and implicit knowledge of organizational participants and articulating them, these common sense understandings can be used to guide designs and decisions about appropriate technology. I will discuss first the basic premise of anthropology (members' competence in organizing a workable world) and then talk about how language studies reveal this.

\section{About the Panelists}

Bonnie Kaplan is a lecturer at the Yale School of Medicine's Center for Medical Informatics, a senior scientist at Boston University's Medical Information Systems Unit, and president of Kaplan Associates. She has published research in change management, organizational issues surrounding the introduction and use of information technologies, 
benefits realization, and evaluating organizational and user acceptance issues pertaining to clinical applications of computer information systems in medicine and health care. She is on the Informatics Advisory Board for a major health care company, serves as Chair of both the American Medical Informatics Association People and Organizational Issues Working Group and the International Medical Informatics Association WG13: Organizational Impacts. She has taught a variety of information systems courses in business administration and hospital administration programs. She holds a Ph.D. in history with a specialization in history of science and medicine from the University of Chicago. Bonnie can be reached by e-mail at bonnie.kaplan@yale.edu.

Jonathan Liebenau is a senior lecturer in Information Systems at the London School of Economics with a background in social studies of science, technology, and medicine. He has published on the application of social science theory to the study of information systems and he teaches a large, year-long doctoral seminar on "Theory and Research Methods in Information Systems." He was a program chair of a recent IFIP 8.2 meeting on "Information Systems and Qualitative Research" and is an editor of the associated volume. His doctorate in history is from the University of Pennsylvania. Jonathan can be reached by e-mail at liebenau@LSE.AC.UK.

Michael D Myers is an associate professor in the Department of Management Science and Information Systems at the University of Auckland. He has a Ph.D. in Social Anthropology from the University of Auckland. Michael has published widely in the areas of qualitative research methods, interpretive research, ethnography, and information systems implementation. He is Editor of the ISWorld Section on Qualitative Research, an Associate Editor of MIS Quarterly, and an Associate Editor of Information Systems Journal. Michael can be reached by e-mail at m.myers@auckland.ac.nz.

Eleanor Wynn is in Applied Information Management at the University of Oregon. She has worked for the past 25 years within the IS, telecommunications, and computer science communities, applying contemporary linguistic and social theories to communications issues surrounding technology development and use. Her interests evolved from a concern with tacit work practices and knowledge sharing to organizational decision-making about technology and then to assumptions embedded in software development methods and practice. Returning to an earlier interest in Latin America, where she was raised, she is now working on a framework for research on globalization and information technology for less-developed countries that follows from all these prior concerns. She received her Ph.D. in 1979 from the University of California Department of Anthropology with a concentration in social interaction. Her doctoral thesis, Office Conversation as an Information Medium, was widely read during the early 1980s when system developers, especially in Europe, were searching for way of studying the workplace that would support a labor-oriented approach. After an internship at Xerox PARC, she worked as a Senior Scientist at Bell-Northern Research and eventually went into private consulting until returning to academic life. She is editor-in-chief of Information Technology \& People. Eleanor can be reached by e-mail at wynn@zephyr.net. 